\title{
Hubungan Dukungan Keluarga Dengan Tingkat Kecemasan Pada Ibu Hamil Primigravida Trimester III Dalam Menghadapi Persalinan
}

\author{
Diani Octaviyanti Handajani ${ }^{1)}$ \\ 1) Prodi Kebidanan, Fakultas Kesehatan, Universitas Muhammadiyah Gresik, Gresik 61111, Indonesia \\ Corresponding Author: Diani Octaviyanti Handajani \\ E-mail: dianiocta190@umg.ac.id
}

\section{INFORMASI ARTIKEL}

Riwayat Artikel:

Submit : 11-09-2021

Revisi : 30-10-2021

Diterima : 30-10-2021

Publikasi : $30-11-2021$

DOI :

http://dx.doi.org/10.30587/ijmt.v111.3321

\section{Keywords:}

Maternal anxiety;

Family support;

Kata Kunci:

Kecemasan ibu hamil;

Dukungan keluarga;

\begin{abstract}
During pregnancy, the mother will experience changes in physical and emotional conditions, which are the main factors for pregnant women, especially primigravida pregnant women. Changes that occur if not handled properly will cause anxiety. Support from the family is needed to deal with the anxiety problems of pregnant women in facing childbirth. This study aims to determine whether there is a relationship between family support and anxiety levels in third trimester primigravida pregnant women who will face childbirth. This research is an analytic observational study with cross sectional approach, with a sample of 30 mothers. The study was conducted at PMB Murtini Surabaya. The data called by quissioner and it was analytical with correlation rank spearman by using SPSS application with $a=0,05$. The results of this study indicate that there is a relationship between family support and anxiety levels in third trimester primigravida pregnant women who are facing labor with the results of rank spearman correlation is $p=0.001$. Postive family support is very important to reduce the level of maternal anxiety in dealing with childbirth.
\end{abstract}

\begin{abstract}
ABSTRAK
Pada masa kehamilan ibu akan mengalami perubahan - perubahan kondisi fisik dan emosional, dimana hal itu merupakan faktor utama ibu hamil khususnya ibu hamil primigravida. Perubahan yang terjadi bila tidak ditangani secara benar akan menimbulkan kecemasan. Dibutuhkanya dukungan dari keluarga untuk menangani masalah kecemasan ibu hamil dalam mengadapi persalinan. Penelitian ini bertujuan untuk mengetahui apakah ada hubungan dukungan keluarga dengan tingkat kecemasan pada ibu hamil primigravida trimester III yang akan menghadapi persalinan. Penelitian ini penelitian Analitik observasional dengan pendekatan cross sectional, dengan sample 30 ibu. Penelitian dilakukan di PMB Murtini Surabaya. Data diambil melalui kuisioner dan dianalisis dengan menggunakan uji staistik correlation rank spearman dengan bantuan aplikasi SPPS dengan $a=0,05$. Hasil penelitian ini menunjukan adanya hubungan dukungan keluarga dengan tingkat kecemasan pada ibu hamil primigravida trimester III yang menghadapi persalinan dengan hasil rank spearman correlation $\mathrm{p}=0.001$. Dukungan keluarga yang positif sangat penting untuk mengurangi tingkat kecemasan ibu dalam menghadapi persalinannya.
\end{abstract}




\section{PENDAHULUAN}

Kehamilan ialah suatu proses normal dan alamiah, setiap wanita akan merasa bahagia ketika ia mengetahui bahwa dirinya akan mempunyai keturunan, tetapi kehamilan merupakan saat kritis bagi wanita dan keluarganya, dimana terjadi perubahan identitas peran ibu, ayah serta anggota keluarga lainya. Sebagian kaum wanita beranggapan bahwa kehamilan adalah suatu peristiwa yang kodrati dan harus dilalui, tetapi sebagian lagi menilai kehamilan sebagai suatu peristiwa yang menentukan pada kehidupan selanjutnya. Pada masa kehamilan ibu akan mengalami perubahan - perubahan kondisi secara fisik dan emosional. Perubahan - perubahan ini terjadi karena perubahan hormon, yang memerlukan adaptasi lebih besar terhadap proses kehamilan dan penyesuaian pola hidup yang terjadi.

Pada ibu hamil primigravida sering mengalami terjadinya kecemasan terutam pada saat menghadapi persalinannya (Maki et al., 2018), makan dari itu ibu hamil memerlukan perhatian dan pikiran yang dianggap memerlukan solusi, sehingga kecemasan serta ketakutan yang dialami ibu hamil menjelang persalinan dapat dihindari. Kecemasan sendiri merupakan suatu keadaan dimana keadaan normal yang dirasakan oleh seseorang mengalami tekanan atau perasaan yang dalam dan dapat memicu terjadinya masalah psikiatris (Shodiqoh et al., 2014). Maramis (2005) juga menyebutkan calon ibu sebagian besar yang sedang menghadapi kelahiran anaknya akan mengalami perasaan takut serta mengalami rasa cemas (Inayah, 2017), seorang ibu mengalami cemas saat akan persalinan dimana merasa khawatir apakah melahirkan dengan normal, apakah anaknya sehat, khawatir akan keselamatannya, takut merasa kehilangan bayinya dan mengalami cemas dalam menghadapi persalinannya (Sangkoy et al., 2020). Kecemasan seorangan ibu dalam menghadapi persalinan ini akan bertambah berat apabila ibu hamil mengalami ketakutan dan akan mengalami perubahan yang drastis yang terjadi pada tubuhnya, bukan hanya fisik tetapi juga psikologisnya (Janiwarty B. P.H.Z, 2012)(Siallagan \& Lestari, 2018). Selain itu kecemasan menurut kuswadi (2002) akan berdampak dari proses fisiologisnya dimana akan timbul perilaku seorang ibu pada kegiatan sehari - hari, ibu hamil akan mudah marah, mudah tersinggung, mengalami gelisah, tidak dapat memusatkan perhatian, kemudian mengalami ragu - ragu, dan kemungkinan bahkan ingin lari dari kenyataan hidup (Utami \& Amalia, 2020). Rasa cemas dan khawatir ibu primigravida pada trimester III ini, akan semakin meningkat pada seorang ibu hamil yang memasuki usia kehamilannya tujuh bulan lebih dan akan menjelang persalinan, dimana ibu hamil akan mulai membayangkan dimana proses persalinan yang merasakan sakit, menegangkan, bahkan dapat terjadi kematian pada saat bersalin (Bahiyatun, 2010). Hal tersebut bila tidak diatasi secara segera akan sangat berpengaruh terhadap keadaan kesehatan janinnya (Sangkoy et al., 2020), karena dengan tingkat kecemasan ibu yang rendah dapat mengurangi komplikasi yang ditimbulkan oleh ibu hamil secara tidak langsung dan dapat mengurangi AKI dan AKB di Indonesia (Siallagan \& Lestari, 2018).

Penelitian yang dilakukan oleh (Cahaya Saputri \& Sujarwo, 2017) menjelaskan bahwa 51 ibu hamil mengalami kecemasan ringan sebanyak (65.38\%), kecemasan sedang 11 ibu hamil $(14.10 \%)$, dan 1 ibu hami mengalami kecemasan berat (1.28). Pencatatan di BPM Murtini pada survei awal yaitu bulan Oktober 2020 - Mei 2021 menunjukkan jumlah ibu hamil yang memeriksakan kehamilannya sebanyak 65 orang ibu hamil, dengan jumlah ibu primigravida sebanyak 42 orang ibu hamil. Berdasarkan hasil observasi awal penelitian di BPM Murtini selama dua hari terdapat 15 ibu hamil yang memeriksakan kehamilanya dan 10 diantaranya adalah ibu primigravida, 7 dari 10 orang ibu primigravida tersebut mengalami kecemasan yang terdiri dari 3 orang mengalami sulit tidur, takut, dukungan keluarga cukup. 2 orang merasa 
tegang, mudah terkejut, mudah menangis, mudah tersinggung dengan dukungan keluarga cukup. Dan 2 orang merasa lemas, sering kencing, jantung berdebar - debar dengan dukungan keluarga kurang. Sedangkan 3 orang lainya tidak mengalami kecemasan dengan dukungan keluarga baik.

Reaksi psikologis pada kehamilan yang pertama kali adalah terjadi suatu krisis maturitas yang dapat mengakibatkan dan menimbulkan stress, dimana mengalami cemas dan merupakan emosi positif untuk perlindungan terhadap stresor yang bisa menjadi masalah apabila berlarut - larut. Kecemasan ini bisa juga membuat ibu merasa lemas, pingsan bahkan dapat memperburuk keadaan, dengan dipengaruhi oleh beberapa faktor yaitu usia, tingkat pengetahuan, pendidikan, pekerjaan, status kesehatan, kurangnya informasi mengenai penyakit, sistem pendukung (dukungan keluarga, suami, orang tua, dukungan tenaga kesehatan) , dukungan keluarga, kebutuhan rasa aman dan nyaman, dan selain itu kecemasan yang timbul saat menghadapi persalinan yaitu perasaan ibu yang tegang, bahkan berdebar - debar dan adanya perasaan sensitive dalam memikirkan proses dari persalinan (Maimunah, A. Retnowati, 2011)

Untuk itu perlu adanya seseorang yang memotivasi pada ibu hamil dalam menghadapi persalinanya, yaitu dengan membesarkan hati, adanya dukungan dari suami dengan menjadi suami yang siaga, dukungan dari keluarga, dan mendapatkan dukungan dari tenaga kesehatan (bidan), sehingga tenaga kesehatan tidak hanya memastikan kondisi kehamilan serta persalinanya ibu tetapi juga dapat menenangkan / menentramkan hati ibu hamil serta membuat ibu lebih lebih tenang dapn siap melakukan persalinan nantinya (Rahmat, D., Karyawati, 2013). Dukungan keluarga dalam hal ini biasanya berupa informasi dan nasehat - nasehat yang mendukung kehamilan ibu, tukar pengalaman salah satu anggota keluarga yang pernah mengalami kehamilan sehingga ibu hamil mempunyai gambaran tentang sikap yang harus diambil dalam menyikapi keadaan kehamilannya serta membantu untuk memenuhi kebutuhan ibu, dan keluarga mengingatkan ibu untuk melakukan pemeriksaan kehamilan secara rutin untuk mengetahui perkembangan kesehatan ibu dan janin serta mendeteksi tanda - tanda bahaya pada kehamilan agar diwaspadai. Dukungan selama persalinan yang diberikan untuk ibu merupakan dukungan dari dukungan emosional dimana ibu menjadikan tenang dalam menghadapi persalinan, meminimalkan terjadinya intervensi, dan dapat menghasilkan persalinan yang baik dan nyaman bagi ibu (Joharia, 2012).

Tujuan dilakukannya penelitian ini adalah untuk menganalisis hubungan antara dukungan keluarga dengan tingkat kecemasan ibu hamil dalam menghadapi persalinannya.

\section{METODE}

Penelitian ini merupakan penelitian Analitik Observasional dengan pendekatan cross sectional. Penelitian ini dilakukan di PMB Murtini yang bertempat di Surabaya. Penelitian dilakukan pada bulan Juni - September 2021. Populasi wanita hamil yang usia kehamilan 28 minggu sampai 40 minggu / Trimester III berjumlah 30 ibu dan sampel pada penelitian ini adalah 30 ibu ditentukan metode total sampling dimana total sampel sama dengan total populasi, dan jumlah dari populasi yang kurang dari 100 maka seluruh dalam populasi dijadikan sampel penelitian.

Alat yang digunakan dalam pengumpulan informasi adalah kuesioner. Informasi yang telah akan diolah serta dianalisis menggunakan tabel distribusi frekuensi untuk analisis univariat dan tabulasi silang untuk analisis bivariate. Analisis hubungan antara variabel dukungan keluarga dan tingkat kecemasan ibu hami dianalisis menggunakan uji statistik correlation rank spearman dengan bantuan aplikasi SPSS dengan tingkat significancy $a=0,05$. 


\section{HASIL PENELITIAN}

\section{Karakteristik Responden}

Tabel 1. Karakteristik Usia Ibu

\begin{tabular}{cccc}
\hline No & Usia & N & $\%$ \\
\hline 1 & $<20$ tahun & 8 & 26.7 \\
2 & $20-30$ tahun & 21 & 70.0 \\
3 & $30-40$ tahun & 1 & 3.3 \\
\hline & Total & 30 & 100 \\
\hline
\end{tabular}

Sumber: data primer, 2021

Tabel 1. Menunjukkan bahwa terdapat 30 ibu sebagian besar usia ibu 20 - 30 tahun yaitu 21 ibu (70.0\%), kemudian usia ibu < 20 tahun sebanyak 8 orang $(26.7 \%)$, dan usai $30-40$ tahun yaitu 1 orang (3.3\%).

Tabel 2. Karakteristik Pendidikan Ibu

\begin{tabular}{clcc}
\hline No & Pendidikan & N & $\%$ \\
\hline 1 & SD & 2 & 6.6 \\
2 & SMP & 5 & 16.7 \\
3 & SMA & 16 & 53.3 \\
4 & Akademi/PT & 7 & 23.4 \\
\hline \multicolumn{2}{c}{ Total } & 30 & 100 \\
\hline
\end{tabular}

Sumber: data primer, 2021

Tabel 2. Menunjukkan bahwa terdapat 30 ibu sebagian besar berpendidikan SMA yaitu 16 orang (53.3\%), pendidikan Akademi/PT 7 orang (23.4\%), pendidikan SMP 5 orang $(16.7 \%)$, dan pendidikan SD 2 orang $(6.6 \%)$.

Tabel 3. Karakteristik Pekerjaan Ibu

\begin{tabular}{clcc}
\hline No & Pekerjaan & $\mathrm{N}$ & $\%$ \\
\hline 1 & Tidak bekerja & 20 & 66.7 \\
2 & Swasta & 8 & 26.7 \\
3 & PNS/ ABRI & 2 & 6.6 \\
\hline & Total & 30 & 100
\end{tabular}

Sumber: data primer, 2021

Tabel 3. Menunjukkan bahwa terdapat 30 ibu sebagian besar tidak bekerja yaitu 20 orang (66.7\%), 8 orang bekerja di swasta (26.7\%), dan bekerja sebagai PNS 2 orang (6.6\%).
Tabel 4. Karateristik Status Ibu Tinggal Bersama Keluarga

\begin{tabular}{clcc}
\hline No & \multicolumn{1}{c}{ Variabel } & $\mathrm{N}$ & $\%$ \\
\hline 1 & $\begin{array}{l}\text { Suami dan } \\
\text { mertua }\end{array}$ & 5 & 16.7 \\
2 & $\begin{array}{l}\text { Suami dan orang } \\
\text { tua }\end{array}$ & 17 & 56.6 \\
3 & Suami & 8 & 26.7 \\
\hline$\quad$ Total & 30 & 100 \\
\hline
\end{tabular}

Sumber: data primer, 2021

Tabel 4. Menunjukkan bahwa terdapat 30 ibu sebagian besar tinggal bersama suami dan orang rumah yaitu 17 orang (56.6\%), tinggal dengan suami 8 orang (26.7\%), tinggal bersama suami dan mertua 5 orang (16.7\%).

\section{Analisis Univariat}

Tabel 5. Distribusi Dukungan Keluarga Pada Ibu Hamil Primigravida Trimester III

\begin{tabular}{clcc}
\hline No & Dukungan Keluarga & $\mathrm{N}$ & $\%$ \\
\hline 1 & $\begin{array}{l}\text { Dukungan Keluarga } \\
\text { Kurang }\end{array}$ & 4 & 13.4 \\
2 & $\begin{array}{l}\text { Dukungan Keluarga } \\
\text { Cukup }\end{array}$ & 15 & 50.0 \\
3 & $\begin{array}{l}\text { Dukungan Keluarga } \\
\text { Baik }\end{array}$ & 11 & 36.6 \\
\hline$\quad$ Total & 30 & 100 \\
\hline
\end{tabular}

Sumber: data primer, 2021

Tabel 5. Menunjukkan bahwa terdapat 30 ibu sebagian besar mempunyai dukungan cukup 15 ibu (50.0\%), dukungan keluarga baik 11 ibu (36.6\%), dukungan keluarga kurang 4 ibu (13.4\%).

Tabel 6. Distribusi Tingkat Kecemasan Pada Ibu Hamil Primigravida Trimester III

\begin{tabular}{cccc}
\hline No & $\begin{array}{c}\text { Tingkat } \\
\text { Kecemasan }\end{array}$ & N & $\%$ \\
\hline 1 & Tidak Cemas & 9 & 30.0 \\
2 & Cemas Ringan & 9 & 30.0 \\
3 & Cemas Sedang & 8 & 26.7 \\
4 & Cemas Berat & 4 & 13.3 \\
\hline \multicolumn{1}{c}{ Total } & 30 & 100 \\
\hline
\end{tabular}

Sumber: data primer, 2021

Tabel 6. Menunjukkan bahwa terdapat 30 ibu sebagian besar 30.0 \% yaitu 9 ibu tidak mengalami kecemasan, 9 ibu $30.0 \%$ mengalami kecemasan ringan, 8 ibu $26.7 \%$ mengalami kecemasan sedang, dan ibu dengan kecemasan berat terdapat 4 ibu $13.3 \%$. 


\section{Analisis Bivariat}

Tabel 7. Tabulasi Silang Hubungan Dukungan Keluarga Dengan Tingkat Kecemasan Pada Ibu Hamil Primigravia Trimester III

\begin{tabular}{|c|c|c|c|c|c|c|c|c|c|c|c|}
\hline \multirow{3}{*}{ No } & \multirow{3}{*}{ Dukungan keluarga } & \multicolumn{8}{|c|}{ Tingkat kecemasan } & \multicolumn{2}{|c|}{ Total } \\
\hline & & \multicolumn{2}{|c|}{ Tidak cemas } & \multicolumn{2}{|c|}{ Ringan } & \multicolumn{2}{|c|}{ Sedang } & \multicolumn{2}{|c|}{ Berat } & & \\
\hline & & $\mathbf{N}$ & $\%$ & $\mathbf{N}$ & $\%$ & $\mathbf{N}$ & $\%$ & $\mathbf{N}$ & $\%$ & $\mathbf{N}$ & $\%$ \\
\hline 1. & Dukungan kurang & 0 & 0 & 2 & 50.0 & 0 & 0 & 2 & 50.0 & 4 & 100 \\
\hline 2. & Dukungan cukup & 6 & 40.0 & 4 & 26.7 & 3 & 20.0 & 2 & 13.3 & 15 & 100 \\
\hline 3. & Dukungan Baik & 3 & 27.2 & 3 & 27.3 & 5 & 45.4 & 0 & 0 & 11 & 100 \\
\hline
\end{tabular}

Sumber: data primer, 2021

Tabel 7. Menunjukan hasil tabulasi silang diatas dapat dilihat bahwa ibu hamil primigravida trimester III yang mendapat dukungan keluarga cukup dengan tidak mengalami kecemasan sebanyak 6 orang $(40.0 \%)$, dan ibu hamil primigravida trimester III yang mendapat dukungan keluarga kurang dengan kecemasan berat sebanyak 2 orang (50.0\%), serta hasil rank sperman correlation $\mathrm{p}=0.001$.

\section{PEMBAHASAN}

Ada dukungan keluarga pada ibu hamil primigravida trimester III menjelang persalinan. Hasil menunjukan ibu yang mendapatkan dukungan keluarga sebagian besar berumur 2030 tahun (70.0\%), berpendidikan SMA (53.3\%), tidak bekerja $(66.7 \%)$, dan tinggal bersama suami dan orang tua (56.6\%). Umur ini merupakan masa peralihan dari remaja menuju dewasa muda, dimana pada masa itulah seseorang baru mengerti arti hidup yang sesungguhnya dan baru mendapat pengalaman berharga. Hal ini berarti pengalaman dan sumber informasi yang dimiliki masih kurang sehingga akan mempengaruhi tingkat pengetahuannya, menurut Hurlock semakin cukup umur tingkat kematangan ibu dan kekuatan ibu akan lebih matang / baik dalam berfikir dan bekerja (Dharmawati \& Wirata, 2016).

Faktor pendidikan juga bisa mempengaruhi tingkat pengetahuan seseorang, karena makin semakin tinggi tingkat pendidikan seseorang, maka makin mudah menerima informasi sehingga makin banyak pula pengetahuan yang dimilikinya. Disaat seseorang berada pada jenjang pendidikan yang rendah boleh dikatakan wawasan dan pola pikirnya masih sederhana, selalu berkeinginan menyelesaikan masalah dengan cepat walau harus menempuh jalan pintas sehingga akan mengalami kesulitan dalam menyerap suatu informasi. Kondisi ini akhirnya akan berdampak pada perkembangan mutu pengetahuan yang dimiliki. Oleh karena itu tingkat pendidikan sangatlah penting bagi ibu hamil khususnya, dengan pendidikan tinggi maka seseorang mendapat pengetahuan tentang kesehatan bagi ibu dan bayinya.

Dari hasil penelitian, tingkat kecemasan ibu hampir setengahnya tidak mengalami cemas $30,0 \%$. Hal ini adanya dukungan keluarga yang baik dan cukup, tetapi masih terdapat kecemasan ringan, dan kecemasan sedang, pada ibu hamil primigravida trimester III meskipun dukungan keluarganya baik. Hal ini disebabkan karena umur yang belum matang atau belum produktif dan pendidikan yang masih rendah. Dari data kuesioner, responden yang mendapat dukungan baik dengan tingkat kecemasan ringan dan kecemasan sedang berumur $\leq 20$ tahun.

Pada umur yang belum matang / produktif seseorang belum siap untuk menghadapi persalinan ini, seseorang masih belum terlatih untuk menghadapi persoalan (belum berpengalaman), belum memiliki cara cara atau solusi yang terbaik dalam memecahkan suatu persoalan, dan bila tidak 
ditangani dengan serius dapat menyebabkan orang cenderung merasakan kecemasan seperti yang dijelaskan oleh Long bahwa semakin tua umur seseorang semakin konstruktif dalam menggunakan koping terhadap masalah yang dihadapi (Pravesty \& Nurmaguphita, 2017).

Selain itu umur, tingkat pendidikan seseorang juga mempengaruhi tingkat kecemasan dalam menghadapi suatu persoalan. Responden yang terdapat tingkat kecemasan berat berpendidikan SMP yang masih tergolong berpendidikan rendah. Dengan tingkat pengetahuan yang rendah, pola pikir seseorang masih kurang dan sederhana (Jennings et al., 2015). Sehingga mengalami kesulitan dalam menerima informasi, akibatnya pengetahuannya kurang mengenai kehamilan dan persalinan dan pada akhirnya sering mengalami kecemasan. Untuk meminimalkan kecemasan agar tidak terjadi kecemasan berat pada ibu hamil primigravida trimester III yaitu dengan memberikan informasi mengenai kehamilan sehingga mereka dapat meningkatkan kemampuan beradaptasi atau mempertahankan diri terhadap lingkungan yang diperoleh dari perkembangan dan pengalamannya, serta beradaptasi terhadap rangsangan atau stressor yang dihadapi.

Ada hubunganya dukungan keluarga dengan tingkat kecemasan pada ibu hamil trimester III pada ibu hamil menjelang persalinan. Dari hasil analisis Rank Spearman Correlation menunjukan hasil $p=0,001$, yang berarti tingkat hubungan yang kuat antara dukungan keluarga dan tingkat kecemasan. Hal ini dilihat dari nilai hitung $(p)=0,000<$ dari $\mathrm{a}=0,05$ dengan demikian $\mathrm{Ha}$ diterima dan $\mathrm{Ho}$ ditolak atau terdapat adanya hubungan dukungan keluarga dengan tingkat kecemasan ibu hamil primigravida dalam menjelang persalinan normal di BPM Murtini, Surabaya.

Dengan adanya dukungan keluarga yang baik akan mengurangi kecemasan pada ibu sehingga proses persalinan lebih lancar, cepat tanpa menimbulkan komplikasi dikemudian, meminimalkan terjadinya intervensi, dan dapat menghasilkan persalinan yang baik dan tidak terjadi hambatan (Joharia, 2012) (Sangkoy et al., 2020). Serta menurut Putri (2012) pentingnya ibu hamil yang akan mejelang persalinan memerlukan dukungan, dikarenakan dukungan keluarga yang diberikan berupa dukuang emosional ini, dapat membantu ibu menghadapi persalinan karena menjadikan ibu lebih tenang, memiliki rasa tanggung jawab terhadap dirinya serta bayi yang akan dilahirkanya (Sangkoy et al., 2020)

\section{SIMPULAN}

Adanya Dukungan Keluarga Dengan Tingkat Kecemasan Pada Ibu Hamil Primigravida Trimester III Dalam Menghadapi Persalinan.

Oleh karena itu, keluarga perlu memberikan dukungan yang positive kepada ibu sehingga ibu dapat meningkatkan kepercayaan diri dan menurunkan tingkat kecemasannya dalam menghadapi persalinannya.

\section{UCAPAN TERIMA KASIH}

Peneliti mengucapkan terimakasih kepada Bidan Murtini di Surabya atas izin yang diberikan untuk peneliti dapat melaksanakan penelitian, serta terima kasih kepada ibu hamil atas izin yang diberikan untuk menjadi responden dalam penelitian ini.

\section{DAFTAR PUSTAKA}

Bahiyatun. (2010). Psikologi ibu dan anak. Jakarta: EGC.

Cahaya Saputri, L., \& Sujarwo, S. (2017). Hubungan antara dukungan keluarga dengan kecemasan menjelang kelahiran anak pertama pada trimestre ketiga. Jurnal Ilmiah PSYCHE, 11(2), 87-96. 
Dharmawati, I. G. A. A., \& Wirata, I. N. (2016). Hubungan Tingkat Pendidikan, Umur, Dan Masa Kerja Dengan Tingkat Pengetahuan Kesehatan Gigi Dan Mulut Pada Guru Penjaskes Sd Di Kecamatan Tampak Siring Gianyar. Jurnal Kesehatan Gigi, 4(1), 1-5. http://www.poltekkes-

denpasar.ac.id/keperawatangigi/wpcontent/uploads/2017/02/ilovepdf_merg ed.pdf

Inayah, S. M. Al. (2017). Tingkat Kecemasan Dalam Menghadapi Persalinan Di Puskesmas Lepo-Lepo Kota Kendari.

Janiwarty B. P.H.Z. (2012). Pendidikan Psikolog Untuk Bidan. Rapha Publishing.

Jennings, C. P., Aldinger, S. G., Kangu, F. N., Jennings, C. P., Purba, J. M., \& Alotaibi, M. N. (2015). No Titleggg. 3(7), 59-78.

Joharia, N. (2012). Asuhan Kebidanan Pada Persalinan Dan Bayi Baru Lahir. Trans Info Media.

Maimunah, A. Retnowati, S. (2011). Pengaruh Pelatihan Relaksasi Dengan Dzikir Untuk Mengatasi Kecemasan Ibu Hamil Pertama. Psikoislamika, Jurnal Psikologi Islam (JPI), $8(1)$.

Maki, F. P., Pali, C., \& Opod, H. (2018). Gambaran Tingkat Kecemasan Ibu Hamil Primigravida Trimester III di Klinik Bersalin Sutra Minahasa Selatan. Jurnal EBiomedik, 6(2), 103-110. https://doi.org/10.35790/ebm.6.2.2018. 21889

Pravesty, E., \& Nurmaguphita, D. (2017). Hubungan Mekanisme Koping Dengan Tingka Stress Pada Orang Tua Yang Memiloki Anak Retardasi Mental di SLLBN 1 Bantul. Journal of Chemical Information and Modeling, 53(9), 1689-1699.

Rahmat, D., Karyawati, Y. (2013). Psikologi Utuk Bidan. Akademia Permata.
Sangkoy, E., Ake, J., \& Jetty, M. (2020). Dukungan Keluarga Terhadap Tingkat Kecemasan Pada Ibu Hamil Primigravida Menjelang Persalinan. E-Jurnal Sariputra, 7(2), 12-16.

Shodiqoh, Roisa, E., Syahrul, \& Fahriani. (2014). Perbedaan Tingkat Kecemasan Dalam Menghadapi Persalinan Antara Primigravida dan Multigravida. Jurnal Berkala Epidemiologi, 2, 141-150.

Siallagan, D., \& Lestari, D. (2018). Tingkat Kecemasan Menghadapi Persalinan Berdasarkan Status Kesehatan, Graviditas Dan Usia Di Wilayah Kerja Puskesmas Jombang. Indonesian Journal of Midwifery (IJM), 1(2), 104-110. https://doi.org/10.35473/ijm.v1i2.101

Utami, V. N., \& Amalia, R. (2020). Jurnal sains kebidanan. Analisis Kepuasan Ibu Bersalin Di Ruang Kebidanan, 2(1), 18-23. 